\title{
Genetic alterations following ionizing radiation in human ovarian cancer-derived endothelial cells
}

\author{
TING LIU ${ }^{1,2}$, XUELIAN DU ${ }^{1}$ and XIUGUI SHENG ${ }^{1}$ \\ ${ }^{1}$ Department of Gynecologic Oncology, Shandong Cancer Hospital, Jinan, Shandong 250117; \\ ${ }^{2}$ Department of Gynecologic Oncology, Linyi Cancer Hospital, Linyi, Shandong 276000, P.R. China
}

Received September 9, 2013; Accepted March 6, 2014

DOI: $10.3892 / \mathrm{mmr} .2014 .2096$

\begin{abstract}
Recent studies have focused on the role of endothelial cells during tumor radiotherapy, and the majority of studies have found that the rate of endothelial cell apoptosis determines the response of the tumor to ionizing radiation treatment. However, gene expression changes in human ovarian cancer-derived endothelial cells in response to X-ray radiation remains poorly understood. The present study was conducted to investigate the radiation-induced gene alterations in human ovarian cancer-derived endothelial cells and to provide novel potential targets for combined anti-angiogenesis and radiation therapy for the treatment of human ovarian cancer. Ovarian cancer-derived endothelial cells, which were harvested from six human ovarian epithelial carcinomas prior to and $4 \mathrm{~h}$ after 400 cGy X-ray irradiation, were analyzed using cDNA microarray technology. Significant genes were selected to corroborate the microarray experiments using a quantitative polymerase chain reaction (qPCR). A total of 28 genes common to all the cDNA microarray results were identified, of which 22 genes were found to be consistently upregulated or downregulated. Thirteen genes were upregulated persistently and nine genes downregulated persistently following irradiation with $400 \mathrm{cGy}$ X-ray in comparison with the matched group. The majority of the significantly altered genes ( $\geq 2$-fold change in expression) were found to have a role in vasculogenesis, cell cycle regulation, inflammation and the immune response, cell growth and apoptosis, nicotinamide metabolism, cell signaling, chemokines and cell adhesion. Eight randomly selected genes were corroborated using qPCR technology. Radiation-induced gene alterations in ovarian cancer-derived endothelial cells and gene-related pathways were associated with vasculogenesis and the radiosensitivity of human ovarian
\end{abstract}

Correspondence to: Dr Xiugui Sheng, Department of Gynecologic Oncology, Shandong Cancer Hospital, 440 Jiyan Road, Jinan, Shandong 250117, P.R. China

E-mail: jnsxg@aliyun.com

Key words: human ovarian cancer, cancer-derived endothelial cells, radiosensitivity, cDNA microarray, anti-angiogenesis cancer, and may provide promising biomarkers for radiation and anti-angiogenesis treatments against ovarian carcinoma.

\section{Introduction}

Angiogenesis, which is essential for solid tumor growth, is a promising target for the treatment of ovarian cancer. The growth and proliferation of cancer cells is dependent on the nutrient supply from the self-supporting vasculature of the neoplasm (1). Angiogenesis has an important role in tumor invasion, migration and susceptibility to radiation (2-4). Additionally, angiogenesis and high expression levels of angiogenic factors are associated with an increased risk of metastasis and recurrence in ovarian cancer (5). The initial stage of angiogenesis depends on endothelial cells sprouting from pre-existing vessels and migrating (6). Endothelial cells self-regulate their growth, as well as regulating the growth of the surrounding tumor cells, through the autocrine and paracrine signaling pathways. In addition, endothelial cells secrete a variety of protease degradation factors that accelerate tumor invasion $(7,8)$. Therefore, the targeting of endothelial cells is a key strategy in the development of anti-angiogenesis therapies for cancer (9)

To date, endothelial cells derived from human ovarian cancer have been extracted, the morphology and invasion characteristics of the cells have been demonstrated and the gene expression profiles of cancer-derived and normal ovarian endothelial cells have been reported (10). Whereas global genetic changes in ovarian cancer-derived endothelial cells have been characterized, there is little information regarding whole genome expression profiling in the ovarian cancer endothelium response to radiotherapy.

Radiotherapy has an important role in neoadjuvant, primary and adjuvant therapy for ovarian cancer. It has been shown that the efficacy of radiotherapy is affected by gene susceptibility (11). A series of genes that are closely associated with radiotherapy has been generated using gene microarray technology and has enhanced the understanding of the pathogenesis and progression of cancer $(10,12)$. The aim of the present study was to screen genes that were closely associated with radiotherapy of ovarian cancer-derived endothelial cells using microarray technology, and to provide novel targets for radiation and anti-angiogenesis combination therapy for the treatment of human ovarian cancer. 


\section{Materials and methods}

Patients and specimens. Fresh specimens of human epithelial ovarian cancer were obtained from six female patients aged 38-61 years, who had undergone surgery for ovarian cancer at the Shandong Cancer Hospital (Jinan, China). Informed consent was obtained from each patient and the use of fresh specimens was approved by the Medical Ethics Committee, Shandong Cancer Hospital. Fresh ovarian specimens were confirmed and diagnosed as ovarian epithelial cancer by a pathologist. Detailed clinicopathological features of each patient are listed in Table I.

Cancer-derived endothelial cell extraction, culture and irradiation. Endothelial cells were isolated from the six epithelial ovarian cancer specimens, in accordance with a previously described protocol (12). The sterile specimens were cut into $0.2-\mathrm{mm}^{3}$ pieces, digested with $0.5 \%$ human collagenase I for $30 \mathrm{~min}$ at $37^{\circ} \mathrm{C}$ and then filtered through a $70-\mu \mathrm{m}$ metal mesh to remove the undigested specimens, followed by a $50-\mu \mathrm{m}$ mesh to yield single cells. Several negative selections were performed, including erythrocyte hemolysis $\left(\mathrm{NH}_{4} \mathrm{Cl}\right)$ and removal of monocytes, lymphocytes and granulocytes using anti-cluster of differentiation (CD)14, -CD45, and -CD64 DynaBeads (Dynal Biotech LLC, Brown Deer, WI, USA). Positive selections were then performed using anti-CD31 immunomagnetic beads using a magnetic separator (Dynal Biotech LLC).

The purified ovarian endothelial cells were incubated in endothelium culture medium which was supplemented with $20 \%$ fetal calf serum, $100 \mathrm{U} / \mathrm{ml}$ streptomycin, $100 \mathrm{U} / \mathrm{ml}$ penicillin, $0.2 \mathrm{U} / \mathrm{ml}$ insulin, $20 \mathrm{ng} / \mathrm{ml}$ basic fibroblast growth factor, $30 \mu \mathrm{g} / \mathrm{ml}$ endothelial cell growth supplement, $10 \mathrm{U} / \mathrm{ml}$ heparin and $5 \mu \mathrm{g} / \mathrm{ml}$ hydrocortisone in a $5 \% \mathrm{CO}_{2}$ incubator at $37^{\circ} \mathrm{C}$. Ovarian endothelial cells in the logarithmic phase were divided into a radiation group and a matched group. Cells in the radiation group were fully exposed for $4 \mathrm{~h}$ to 6 MV 400 cGy X-rays.

Immunofluorescence staining. Ovarian endothelial cells were incubated for $24 \mathrm{~h}$, washed with cold phosphate-buffered saline (PBS) and fixed with $4 \%$ paraformaldehyde solution for $25 \mathrm{~min}$. The cells were subsequently washed again with cold PBS, prior to being permeabilized with $0.5 \%$ Triton X-100 for $15 \mathrm{~min}$, blocked with $1 \%$ bovine serum albumin for $30 \mathrm{~min}$ at $37^{\circ} \mathrm{C}$ and incubated with rabbit anti-human von Willebrand factor (vWF) antibody (Immuno Way, Newark, DE, USA) for $10 \mathrm{~h}$ at $4^{\circ} \mathrm{C}$ in sequence. Following washing, fluorescein isothiocyanate-labeled goat anti-rabbit immunoglobulin $\mathrm{G}$ (1:100) was added for $1 \mathrm{~h}$ and 4',6-diamidino-2-phenylindole (Sigma, St Louis, MO, USA) for 3-5 min.

RNA isolation and oligonucleotide array sequence analysis. Total RNA was extracted from ovarian endothelial cells using the RNeasy-Mini kit (Qiagen, Hilden, Germany) and was purified using the RNase-free DNase Set (Qiagen, Valencia, CA, USA) according to the manufacturer's instructions. The quality and quantity of the extracted total RNA were assessed using gel electrophoresis and the ratio of the optical density at 260 and $280 \mathrm{~nm}$, respectively.
Total RNA, which was extracted from unirradiated and irradiated ovarian endothelial cells, was reverse transcribed to cDNA and labeled with Cy5- and Cy3-deoxycytidine triphosphate, respectively. The Cy5- and Cy3-labeled cDNAs were hybridized to the Human Genome U133 Plus 2.0 Affymetrix oligonucleotide microarray (Affymetrix, Inc., Santa Clara, CA, USA). Arrays were scanned using a LuxScan ${ }^{\mathrm{TM}}$ scanner (CapitalBio Corporation, Beijing, China) and the images obtained were analyzed using the LuxScan 3.0 software (CapitalBio) using a LOWESS normalization method. To enhance the accuracy of the data analysis, dye swap hybridizations were performed and the average ratio of $\mathrm{Cy} 5 / \mathrm{Cy} 3$ was calculated to evaluate the gene expression levels. Signaling pathways that were associated with significant alterations were identified using the pathway analysis software MAS 2.0 (accessed at www.capitalbio.com).

Quantitative polymerase chain reaction ( $q P C R$ ). To confirm the results from the microarray assay, $\mathrm{qPCR}$ was performed using a SYBR Green RT-PCR kit (Applied Biosystems, Foster City, CA, USA) in accordance with the manufacturer's instructions for the ABI Prism 7000 system (Applied Biosystems). Eight genes, chemokine (C-X-C motif) ligand 12 (CXCL12); matrix metallopeptidase 2 (MMP2); interleukin 7 receptor (IL7R); nicotinamide N-methyltransferase (NNMT); insulin-like growth factor 1 (IGF1); oncostatin M (OSM); cyclin D1 (CCND1) and thrombospondin 1 (THBS1), were used to validate the microarray data. All the primer sequences that were designed for these genes are shown in Table II. The total RNA extraction method was performed as mentioned above, and the purified RNA was then reverse transcribed to cDNA in accordance with the Fermentas RT kit instructions (Applied Biosystems). qPCR was performed under the following conditions: Holding at $95^{\circ} \mathrm{C}$ for $10 \mathrm{~min}$, followed by 40 cycles, which included preliminary denaturing at $95^{\circ} \mathrm{C}$ for $10 \mathrm{sec}$, annealing at $55^{\circ} \mathrm{C}$ for $10 \mathrm{sec}$ and extension at $72^{\circ} \mathrm{C}$ for $15 \mathrm{sec}$. All qPCR reactions were performed in triplicate. The reaction data from the qPCR were evaluated using melting-curve analysis and agar gel electrophoresis sugar, respectively. The cycle threshold $(\mathrm{Ct})$ method was used to calculate the relative level of gene expression and the $2^{-\triangle \Delta C T}$ method was used to calculate the average $\mathrm{Ct}$ values. These $\mathrm{Ct}$ values were normalized against GAPDH, which was used as internal control (13).

Statistical analysis. Data were analyzed using SPSS 17.0 statistical software (SPSS, Inc., Chicago, IL, USA). Statistical differences between the two groups were analyzed using the Student's t-test and evaluated using $\mathrm{P}$-values. $\mathrm{P}<0.05$ was considered to indicate a statistically significant difference.

\section{Results}

Ovarian endothelial cell characteristics. Primary-cultured ovarian microvascular endothelial cells, which contained anti-CD31 magnetic beads, exhibited the contact inhibition phenomenon and presented a typical cobblestone morphology (Fig. 1). The classical endothelial marker, vWF, was expressed in cancer-derived (Fig. 2A) and normal (Fig. 2B) ovarian microvascular endothelial cells, as demonstrated using the immunofluorescence assay. 
Table I. Characteristics of patients with ovarian epithelial cancer whose samples were used to extract endothelial cells.

\begin{tabular}{llcc}
\hline Pathological pattern & Neoplasm staging & Age (years) & Gene microarray \\
\hline Serous adenocarcinoma & Stage IIIb & 48 & + \\
Serous adenocarcinoma & Stage IIIa & 61 & + \\
Serous adenocarcinoma & Stage IIc & 56 & + \\
Serous adenocarcinoma & Stage IIIb & 38 & + \\
Serous adenocarcinoma & Stage IIc & 55 & + \\
Serous adenocarcinoma & Stage IIIc & 53 & + \\
\hline
\end{tabular}

+ , microarray/qPCR was performed. qPCR, quantitative polymerase chain reaction.

Table II. Oligonucleotides used for quantitative polymerase chain reaction.

\begin{tabular}{|c|c|c|c|}
\hline Gene name & Gene bank ID & Primer sequence ( $5^{\prime}$ to $\left.3^{\prime}\right)$ & Product length (bp) \\
\hline CXCL12 & NM_199168.3 & $\begin{array}{l}\text { F-gattcttcgaaagccatgttg } \\
\text { R-cactttagcttcgggtcaatg }\end{array}$ & 136 \\
\hline MMP2 & NM_004530 & $\begin{array}{l}\text { F-tgacatcaagggcattcaggag } \\
\text { R-tctgagcgatgccatcaaataca }\end{array}$ & 134 \\
\hline CCND1 & NM_053056 & $\begin{array}{l}\text { F-gtgaagttcatttccaatccgc } \\
\text { R-gggacatcaccctcacttac }\end{array}$ & 167 \\
\hline NNMT & NM_006169.2 & $\begin{array}{l}\text { F-agactccttcttcagccaacat } \\
\text { R-accccaaagttcagagagacag }\end{array}$ & 197 \\
\hline OSM & NM_020530 & $\begin{array}{l}\text { F-catcgaggacttggagaagc } \\
\text { R-tcagccgtgtctgagttgtc }\end{array}$ & 105 \\
\hline IL7R & NM_002185 & $\begin{array}{l}\text { F-gacgcccetattctctcctc } \\
\text { R-taagaatgggctgaccetca }\end{array}$ & 184 \\
\hline IGF1 & NM_000618 & $\begin{array}{l}\text { F-cctcctcgcatctcttctacetgc } \\
\text { R-tgctggagccataccetgtg }\end{array}$ & 166 \\
\hline THBS1 & NM_003246.2 & $\begin{array}{l}\text { F-gacatcccaaaatgaccctaac } \\
\text { R-acttgcttccacatcacaacat }\end{array}$ & 222 \\
\hline GAPDH & NM_002046 & $\begin{array}{l}\text { F-ggaaggtgaaggtcggagtct } \\
\text { R-gtcattgatggcaacaatatccact }\end{array}$ & 101 \\
\hline
\end{tabular}

CXCL12, chemokine(C-X-Cmotif) ligand 12;MMP2, matrix metallopeptidase 2; CCND1, cyclin D1; NNMT, nicotinamideN-methyltransferase; OSM, oncostatin M; IL7R, interleukin 7 receptor; IGF1, insulin-like growth factor 1; THBS1, thrombospondin 1; F, forward; R, reverse.

Significantly upregulated and downregulated genes in ovarian endothelial cells. The cDNA microarray assay analysis was used to identify significant gene alterations following 400 cGy X-ray irradiation in primary cultured human ovarian cancer-derived microvascular endothelial cells. A total of 28 genes were identified in all independent experiments, and 22 genes were found to be significantly and consistently up- or downregulated ( $\geq 2$-fold). Of all the differentially expressed genes, 13 genes were upregulated whilst nine were downregulated following $400 \mathrm{cGy} \mathrm{X}$-ray irradiation in comparison with the control group (Tables III and IV). The majority of genes identified that were significantly altered ( $\geq 2$-fold) were involved in the regulation of cell cycle (CCND1), cell adhesion (sialic acid binding Ig-like lectin 1, MMP9, MMP2 and MMP1), regulation of cell growth [IGF1, platelet-derived growth factor C (PDGFC), FBJ murine osteosarcoma viral oncogene homolog and TIMP metallopeptidase inhibitor 1], the immune response (major histocompatibility complex, class I, E and IL7R), apoptosis (DNA damage-binding protein 2 and FILIP1L), chemokines [chemokine (C-C motif) ligand 2 (CCL2), CCL8, CXCL1, CXC receptor 4 (CXCR4) and $\mathrm{CXCL12}$, the inflammatory response [interleukin 6 (IL6) and IL18], growth factors (PDGFC, platelet-derived endothelial cell growth factor, tumor necrosis factor (ligand) superfamily, member $13 \mathrm{~b}$ and growth differentiation factor 15), nicotinamide metabolism (NNMT), cell signaling (IGF1) and angiogenesis [thrombospondin 1 (THBS1)].

Pathway analysis. The interworking network of these gene-associated pathways, integrating information 

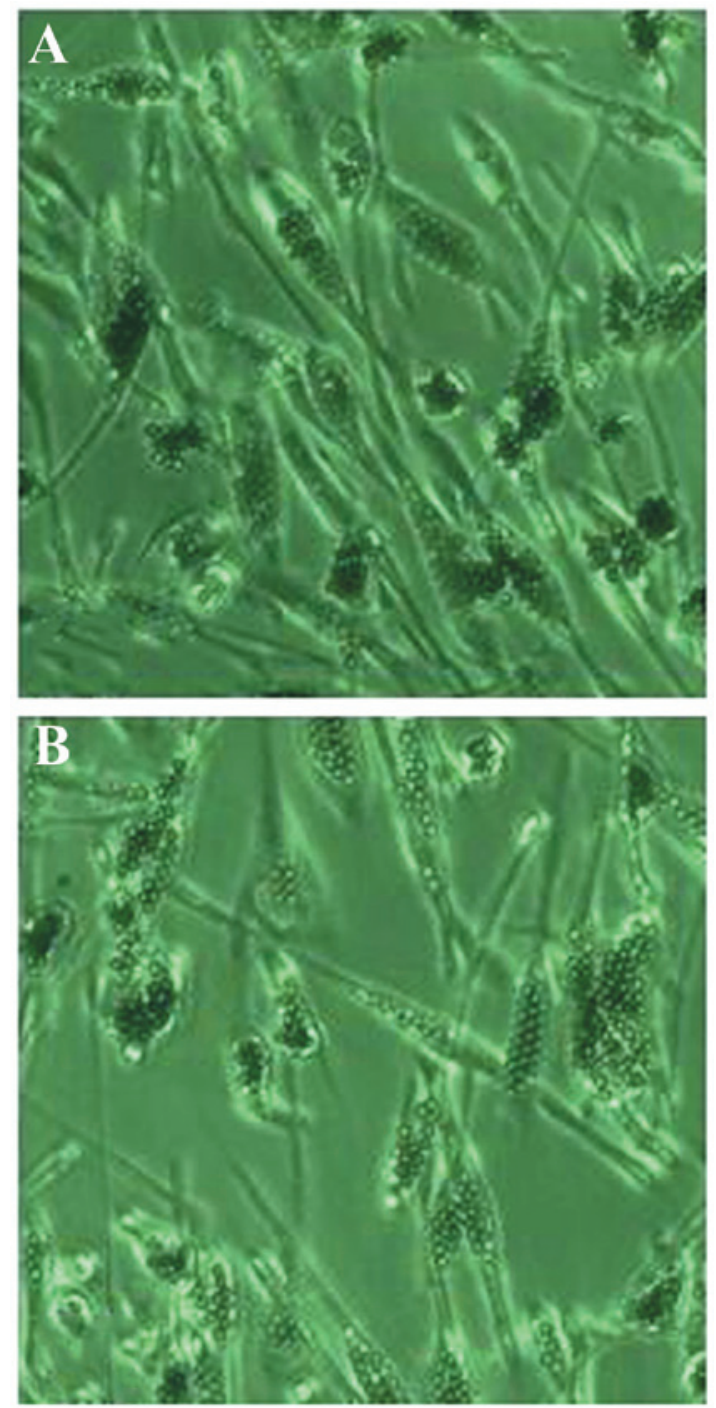

Figure 1. Morphology and characterization of primary cultured ovarian cancer-derived purified endothelial cells. (A) Cancer-derived and (B) normal ovarian endothelial cells (magnification, $\mathrm{x} 200$ ). All endothelial cells contained anti-cluster of differentiation 31 immunomagnetic beads, had a typical cobblestone pattern and exhibited contact inhibition.

from the Kyoto Encyclopedia of Genes and Genomes (www.genome.jp/kegg), Gene Map Annotator and Pathway Profiler (www.genmapp.org) and BioCarta (www.biocarta.com), are listed in Table V. Gene ontology analysis showed that the chemokine and NOD-like receptor signaling pathways were the most important.

Corroboration of microarray data using $q P C R$. Eight genes, which had different fold changes in expression, were randomly selected to corroborate the reproducibility of the cDNA microarray analysis results using a two-step fluorescent qPCR method. Upregulated genes comprised CXCL12 (7.64-fold), MMP2 (8.12-fold), IL7R (9.81-fold), NNMT (5.56-fold), IGF1 (4.06-fold) and THBS1 (3.77-fold), and downregulated genes comprised OSM (4.18-fold) and CCND1 (4.73-fold). The two-step qPCR was arranged so that each independent experiment was performed at least three times; the analysis results are shown in Fig. 3. The results from the qPCR were consistent with those from the micro-
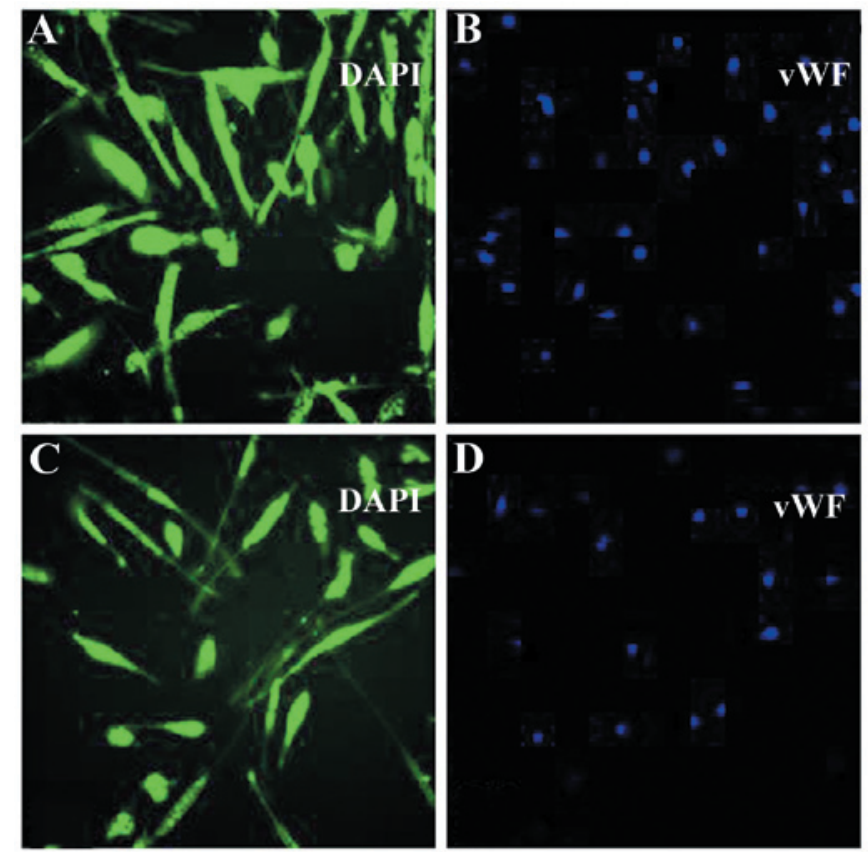

Figure 2. vWF immunofluorescence for ovarian cancer-derived endothelial cells. Normal ovarian endothelial cells were used as the control group (A and C) DAPI staining of (A) ovarian cancer-derived and (C) normal ovarian endothelial cells; (B and D) vWF immunofluorescence for (B) ovarian cancer derived and (D) normal ovarian endothelial cells. Magnification, $\mathrm{x} 400$. The nuclei were stained using DAPI. vWF, von Willebrand factor.

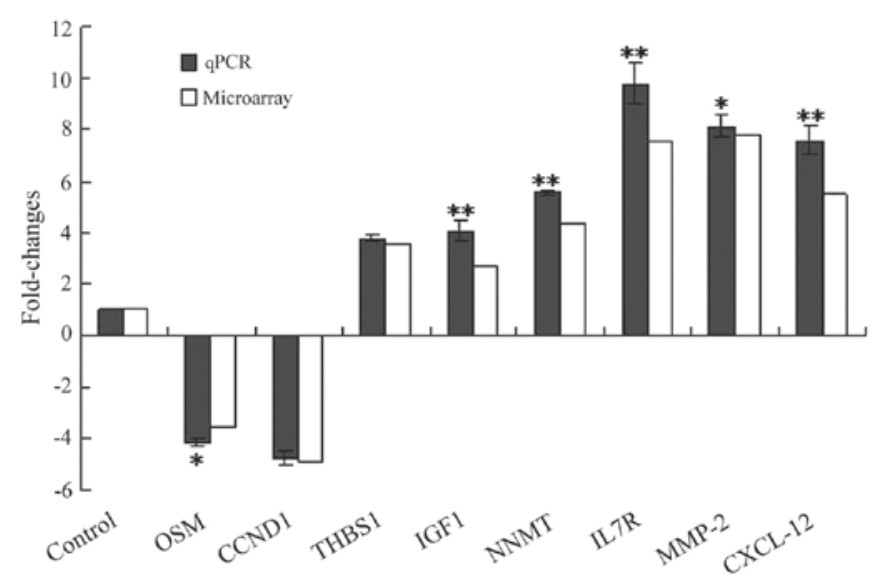

Figure 3. qPCR validation of the cDNA microarray data. All qPCR results were consistent with data obtained from gene microarray. qPCR was performed in triplicate and the ratios of statistics were calculated relative to the internal control gene GAPDH ( $\mathrm{P}<0.05,{ }^{* *} \mathrm{P}<0.01$ vs. control). OSM, oncostatin M; CCND1, cyclin D1; THBS1, thrombospondin 1; IGF1, insulin-like growth factor 1; NNMT, nicotinamide N-methyltransferase; IL7R, interleukin 7 receptor; MMP2, matrix metallopeptidase 2; CXCL12, chemokine (C-X-C motif) ligand 12; qPCR, quantitative polymerase chain reaction.

array analysis and supported the reproducibility of the gene microarray data.

\section{Discussion}

In the present study, gene alterations in human ovarian cancer-derived microvascular endothelial cells in response to 400 cGy X-ray irradiation were identified using cDNA 
Table III. Upregulated genes in ovarian cancer endothelial cells following 400c Gy X-ray irradiation.

\begin{tabular}{|c|c|c|c|c|}
\hline Gene & Accession number & Description & Function & Fold change \\
\hline IL6 & NM_000600 & Human interleukin 6 & $\begin{array}{l}\text { Participation in a wide variety of } \\
\text { inflammation-associated disease } \\
\text { states }\end{array}$ & 7.3687 \\
\hline IL7R & NM_002185 & Human interleukin 7 receptor & Receptors of various cytokines & 7.5758 \\
\hline THBS1 & NM_003246 & Thrombospondin 1 & $\begin{array}{l}\text { Participation in platelet aggregation } \\
\text { tion, angiogenesis and tumorigenesis }\end{array}$ & 3.5428 \\
\hline CXCL12 & NM_199168 & $\begin{array}{l}\text { Chemokine }(\mathrm{C}-\mathrm{X}-\mathrm{C} \text { motif }) \\
\text { ligand } 12, \text { transcript variant } 1\end{array}$ & $\begin{array}{l}\text { Regulation of hematopoietic cell } \\
\text { trafficking and lymphoid tissue } \\
\text { architecture; associated with tumor } \\
\text { metastasis }\end{array}$ & 5.5243 \\
\hline MMP2 & NM_004530 & Matrix metallopeptidase 2 & $\begin{array}{l}\text { Breaking down the extracellular } \\
\text { matrix; regulation of vascularization } \\
\text { and the inflammatory response }\end{array}$ & 7.8264 \\
\hline NNMT & NM_006169 & $\begin{array}{l}\text { Human nicotinamide } \\
\text { N-methyltransferase }\end{array}$ & $\begin{array}{l}\text { Participating in nicotinamide } \\
\text { metabolism }\end{array}$ & 4.3794 \\
\hline SIGLEC1 & NM_023068 & $\begin{array}{l}\text { Human sialic acid binding Ig-like } \\
\text { lectin } 1 \text {, sialoadhesin }\end{array}$ & $\begin{array}{l}\text { Involved in mediating cell-cell } \\
\text { interactions }\end{array}$ & 2.2145 \\
\hline IGF1 & NM_000618 & $\begin{array}{l}\text { Human insulin-like growth } \\
\text { factor } 1\end{array}$ & $\begin{array}{l}\text { Involved in mediating growth and } \\
\text { development }\end{array}$ & 2.6647 \\
\hline MMP9 & NM_004994 & $\begin{array}{l}\text { Matrix metallopeptidase } 9 \\
\text { (gelatinase B, } 92 \mathrm{kDa} \text { gelatinase, } \\
92 \mathrm{kDa} \text { type IV collagenase) }\end{array}$ & $\begin{array}{l}\text { Breaking down the extracellular } \\
\text { matrix; leukocyte migration }\end{array}$ & 6.8237 \\
\hline CXCR4 & NM_003467 & $\begin{array}{l}\text { Human chemokine (C-X-C motif) } \\
\text { receptor } 4\end{array}$ & $\begin{array}{l}\text { CXC chemokine receptor specific for } \\
\text { stromal cell-derived factor- } 1\end{array}$ & 3.3782 \\
\hline PDGFC & NM_016205 & Platelet-derived growth factor $\mathrm{C}$ & Growth factor & 2.03531 \\
\hline TIMP1 & NM_003254 & $\begin{array}{l}\text { Human TIMP metallopeptidase } \\
\text { inhibitor } 1\end{array}$ & $\begin{array}{l}\text { Involved in degradation of the } \\
\text { extracellular matrix; promoting cell } \\
\text { proliferation in a wide range of cell } \\
\text { types; anti-apoptotic function }\end{array}$ & 2.5746 \\
\hline DDB2 & NM_000107 & $\begin{array}{l}\text { Damage-specific DNA binding } \\
\text { protein } 2,48 \mathrm{kDa}\end{array}$ & $\begin{array}{l}\text { Facilitates the cellular response to } \\
\text { DNA damage }\end{array}$ & 2.4747 \\
\hline
\end{tabular}

microarray analysis and qPCR technology. Following treatment with 400 cGy X-ray irradiation, a total of 28 genes were found to be differentially expressed ( $\geq 2$-fold) in primary cultured ovarian cancer-derived endothelial cells compared with the control group. A number of significant genes and gene clusters were revealed in the present study, and these genes and gene clusters were found to be associated with tumor angiogenesis, cell cycle regulation, inflammation and the immune response, cell growth and apoptosis, nicotinamide metabolism, cell signaling, chemokines and cell adhesion. Radiation-induced gene alterations and gene-related pathways in endothelial cells may provide the theoretical basis for the combination of radiation and anti-angiogenesis therapy for the treatment of human ovarian cancer.

Radiotherapy exerts a cytotoxic effect on malignant tumors; however, low-dose radiation may induce neovascularization (14). In the present study, the expression of genes in the chemokine family, which activate the neoplasm-related immunoreaction, regulate neoplasm vasculogenesis and participate in neoplasm growth and metastasis, were found to be significantly modified (15). These altered chemokine-associated genes included
CXCL1, CXCL12, CXCR4, CCL2 and CCL8. Wolff et al (16) showed a consistent upregulation pattern of CXCL1, CXCL12 and CXCR4 in head and neck tumor cells following X-ray irradiation. Kryczek et al (17) used an athymic mouse model to demonstrate that inhibition of the CXCL12/CXCR4 axis may inhibit human spongioblastoma regrowth following radiotherapy. CXCL1, CXCR4 and other chemokines were observed to be in an upregulated state when human umbilical vein endothelial cells were exposed to low-dose ionizing radiation (18). The data from the present study suggest that chemokines may have the potential to be targets for radiation and anti-vasculogenesis therapies for the treatment of ovarian cancer.

MMPs are known to be associated with neoplasm vasculogenesis and invasion. In the present study, it was found that MMP-2 and MMP-9 were overexpressed in radiation-induced ovarian cancer-derived endothelial cells. MMP-2 and MMP-9 overexpression has been found to be closely associated with ovarian cancer invasion and metastasis (19). Peng et al (20) reported that decreased MMP-2 and MMP-9 expression was associated with reduced angiogenesis in radiation therapy for nasopharyngeal carcinoma (20). Pratheeshkumar and 
Table IV. Downregulated genes in ovarian cancer-derived endothelial cells following 400 cGy X-ray irradiation.

\begin{tabular}{|c|c|c|c|c|}
\hline Gene & Accession number & Description & Function & Fold change \\
\hline IL18 & NM_001562 & $\begin{array}{l}\text { Human interleukin } 18 \\
\text { (interferon- } \gamma \text {-inducing } \\
\text { factor) }\end{array}$ & Pro-inflammatory cytokine & 0.2495 \\
\hline MMP1 & NM_002421 & $\begin{array}{l}\text { Matrix metallopeptidase } 1 \\
\text { (interstitial collagenase) }\end{array}$ & Breakdown of extracellular matrix & 0.3195 \\
\hline FOS & NM_005252 & $\begin{array}{l}\text { FBJ murine osteosarcoma } \\
\text { viral oncogene homolog }\end{array}$ & $\begin{array}{l}\text { Regulators of cell proliferation, } \\
\text { differentiation and transformation }\end{array}$ & 0.4872 \\
\hline CCL8 & NM_005623 & $\begin{array}{l}\text { Human chemokine }(\mathrm{C}-\mathrm{C} \\
\text { motif) ligand } 8\end{array}$ & Anti-viral & 0.0839 \\
\hline CXCL1 & NM_001511 & $\begin{array}{l}\text { Chemokine (C-X-C motif) } \\
\text { ligand } 1 \text { (melanoma growth } \\
\text { stimulating activity, } \alpha)\end{array}$ & Chemokine & 0.3764 \\
\hline CCL2 & NM_002982 & $\begin{array}{l}\text { Human chemokine }(\mathrm{C}-\mathrm{C} \\
\text { motif) ligand } 2\end{array}$ & $\begin{array}{l}\text { Involved in immunoregulatory and } \\
\text { inflammatory processes }\end{array}$ & 0.1361 \\
\hline FILIP1L & $\begin{array}{l}\text { NM_001042459.1 } \\
\text { NM_014890.2 }\end{array}$ & $\begin{array}{l}\text { Filamin A interacting } \\
\text { protein 1-like }\end{array}$ & Apoptosis-mediated & 0.3363 \\
\hline OSM & NM_020530 & Human oncostatin M & $\begin{array}{l}\text { Inhibition of the proliferation of tumor cell } \\
\text { lines; regulating cytokine production, } \\
\text { including IL-6, G-CSF and GM-CSF from } \\
\text { endothelial cells }\end{array}$ & 0.2793 \\
\hline CCND1 & NM_053056 & Human cyclin D1 & $\begin{array}{l}\text { Interacting with tumor suppressor protein } \\
\mathrm{Rb} \text {; altering cell cycle progression }\end{array}$ & 0.2021 \\
\hline
\end{tabular}

G-CSF, granulocyte-colony stimulating factor; GM-CSF, granulocyte-macrophage colony-stimulating factor.

Table V. Significant gene-related pathways involved in radiosensitivity of human ovarian cancer-derived endothelial cells.

\begin{tabular}{|c|c|c|}
\hline Pathway & Gene & P-value \\
\hline Cytokine-cytokine receptor interaction & $\begin{array}{l}\text { IL6, CCL2, CCL8, CXCL1, CXCL12, } \\
\text { CXCR4, PDGFC, IL7R, IL18, OSM }\end{array}$ & $1.97 \times 10^{-9}$ \\
\hline Chemokine signaling pathway & CCL2, CXCL1, CCL8, CXCL12, CXCR4 & $1.24 \times 10^{-4}$ \\
\hline NOD-like receptor signaling pathway & CXCL1, CCL2, IL18, CCL8 & 0.0023 \\
\hline Jak/STAT signaling pathway & OSM, CCND1 & 0.041574 \\
\hline Toll-like receptor signaling pathway & FOS & 0.150482 \\
\hline ECM-receptor interaction & THBS1 & 0.021324 \\
\hline TGF- $\beta$ signaling pathway & THBS1 & 0.180432 \\
\hline p53 signaling pathway & CCND1, DDB2, IGF1, THBS1 & 0.049089 \\
\hline Focal adhesion & CCND1, TNC, IGF1, PDGFC, THBS1 & 0.077215 \\
\hline Toll-like receptor signaling pathway & FOS, IL6 & 0.080742 \\
\hline Cell adhesion molecules & SIGLEC1 & 0.099162 \\
\hline
\end{tabular}

Kuttan (21) demonstrated that vernolide-A was capable of inhibiting radiation-induced neoplasm vasculogenesis by downregulating the angiogenic growth factors MMP-2 and MMP-9. Radiation-induced neoplasm vasculogenesis has also been successfully suppressed by MMP-2 and MMP-9 inhibitors $(22,23)$. Therefore, MMP inhibitors, in combination with radiotherapy, may be a novel therapeutic strategy for the treatment of ovarian carcinoma. 
The cytokine IL-6, which is an important regulator of tumor progression, has a pro-proliferative effect on endothelial cells (24). Pre-clinical trials have shown that the overexpression of IL-6 is associated with multidrug resistance, via the Janus kinase/signal transducer and activator of transcription (Jak/STAT) signaling pathway, and poor prognosis in ovarian cancer cells $(25,26)$. In the present study, it was found that IL-6 was present in a high-expression state in ovarian cancer-derived endothelial cells in response to 400 cGy X-ray irradiation. Recently, Oh et al (27) found that the IL-6 gene was upregulated in breast cancer-derived endothelial cells following X-ray irradiation and knockdown of the c-jun $\mathrm{N}$-terminal kinase or Akt signal transduction pathways using small interfering RNA (siRNA) to effectively attenuate the expression of IL-6 in irradiated endothelial cells. Yu et al (28) demonstrated using cytokine array analysis that the secretion of IL-6 increased in radiation-induced senescent cells, and it was shown using siRNA technology that the upregulated IL-6 expression accelerated tumor cell invasion. Despite this, the potential mechanisms of IL- 6 in irradiated ovarian cancer-derived endothelial cells require further investigation.

THBS1, an effective neoplasm vasculogenesis inhibitor, is the target gene of the thrombospondin 1 (TSP1) protein. It has been shown that TSP1 can suppress cancerous cell growth by preventing vascular endothelial cells from coping with multiple vasculogenesis-stimulating factors. Rofstad et al (29) demonstrated that TSP1 not only prevented the development of distant disseminated micro-metastases following radiotherapy, but also inhibited the regrowth of radiated primary human melanoma. The results from their study also confirmed that TSP1 may improve the susceptibility of human melanoma to radiation by enhancing the frequency of the cancer-associated endothelial cell apoptosis. Furthermore, Maxhimer et al (30) demonstrated that blocking the TSP1/CD47 pathway may protect the surrounding healthy tissue from radiolesion and improve tumor radiosensitivity. TSP1 acts via CD47 to inhibit the nitric oxide/cyclic guanosine monophosphate pathway, which may promote endothelial cell proliferation and survival (30-32). In the present study, it was found that THBS1 showed high levels of expression in ovarian cancer-derived endothelial cells following 400 cGy X-ray irradiation, compared with levels in control cells (3.54-fold increase). This suggests that THBS1 was the main factor enhancing the curative effect of radiotherapy in ovarian cancer-derived endothelial cells.

The FILIP1L gene, originally known as 'downregulated in ovarian cancer' or DOC1, has been previously demonstrated to be downregulated in various human malignant tumors and, in the present study, low expression levels were observed. Kwon et al (33) confirmed that the overexpression of FILIP1L has an important role in inhibiting cell proliferation and inducing apoptosis in human umbilical vein endothelial cells transfected with FILIP1L cDNA. Lu and Hallstrom (34) demonstrated that treatment with topoisomerase II chemotherapeutic agents induced FILIP1L expression in an ataxia telangiectasia mutated/ataxia telangiectasia and Rad3-related protein-dependent manner, and that the increased FILIP1L expression enhanced the sensitivity of human osteosarcoma cells to topoisomerase II chemotherapeutic agents. To the best of our knowledge, the present study is the first to demonstrate changes in FILIP1L gene expression in human ovarian cancer-derived endothelial cells in response to X-ray radiotherapy. Whether the FILIP1L gene is an effective radiation and anti-vasculogenesis therapy target requires further investigation; however, its function in ovarian endothelial cells and its antitumor effect make it a promising candidate gene.

Another gene of note is NNMT, which exhibited a high-expression state in the present study (4.13-fold increase in expression compared with control cells) and is widely known to participate in nicotinate and nicotinamide metabolism (35). It has been shown that nicotinamide can enhance the radiation response of human spongioblastoma in a Nude mouse model, and nicotinamide has also been shown to increase sensitivity to radiation in patients with bladder cancer $(36,37)$. This suggests that NNMT expression is associated with the radiation response. Kassem et al (38) demonstrated that NNMT exhibited low expression levels in a radiosensitive cell line. However, the specific mechanism linking radiosusceptibility and NNMT in ovarian cancer has yet to be elucidated.

In the present study, signaling pathways that were associated with significant alterations in gene expression in vascular endothelial cells in response to X-ray radiation were identified using the pathway analysis software MAS 2.0. The majority of the pathways identified were found to be involved in cell proliferation and differentiation, cell adhesion, extracellular matrix regulation and cell migration, including the NOD-like receptor signaling pathway, the chemokine signaling channel and the Jak/STAT signaling pathway. The data from the present study suggest that these pathways may participate in regulating the behavior of ovarian cancer-derived endothelial cells following radiotherapy. However, the roles of these pathways in ovarian cancer radiotherapy remain inconclusive and require further investigation.

In conclusion, genes altered by $\mathrm{X}$-ray radiation in human ovarian cancer-derived endothelial cells were identified in the present study. These genes were involved in angiogenesis, cell cycle regulation, inflammation and the immune response, cell growth and apoptosis, nicotinamide metabolism, cell signaling, chemokines and cell adhesion. The findings from the present study may be useful, not only to provide the theoretical foundation to predict anti-angiogenesis- and radiosensitivity-associated genes, but also as a means to identify potential and effective targets to improve the radiosensitivity of ovarian cancer cells. In future studies, additional investigations are required to define the role of these identified genes in vitro and in vivo.

\section{Acknowledgements}

This study was supported by the National Natural Science Foundation of China (no. 30901713).

\section{References}

1. Folkman J: What is the evidence that tumors are angiogenesis dependent? J Natl Cancer Inst 82: 4-6, 1990.

2. Carmeliet P and Jain RK: Angiogenesis in cancer and other diseases. Nature 407: 249-257, 2000.

3. Folkman J: Angiogenesis in cancer, vascular, rheumatoid and other disease. Nat Med 1: 27-31, 1995.

4. Fuks Z and Kolesnick R: Engaging the vascular component of the tumor response. Cancer Cell 8: 89-91, 2005. 
5. Cooper BC, Ritchie JM, Broghammer CL, et al: Preoperative serum vascular endothelial growth factor levels: significance in ovarian cancer. Clin Cancer Res 8: 3193-3197, 2002.

6. Davis GE and Senger DR: Endothelial extracellular matrix: biosynthesis, remodeling, and functions during vascular morphogenesis and neovessel stabilization. Circ Res 97: 1093-1107,2005.

7. Hu Z, Lin D, Yuan J, et al: Overexpression of osteopontin associated with more aggressive phenotypes in human non-small cell lung cancer. Clin Cancer Res 11: 4646-4652, 2005.

8. Eto M, Kodama S, Nomi N, Uemura N and Suzuki M: Clinical significance of elevated ostopontin levels in head and neck cancer patients. Auris Nasus LaryU 34: 343-346, 2007.

9. Kerbel R and Folkman J: Clinical translation of angiogenesis inhibitors. Nat Rev Cancer 2: 727-739, 2002.

10. Lu C, Bonome T, Li Y, Kamat AA, et al: Gene alterations identified by expression profiling in tumor-associated endothelial cells from invasive ovarian carcinoma. Cancer Res 67: 1757-1768, 2007.

11. Peltenburg LT: Radiosensitivity of tumor cells. Oncogenes and apoptosis. Q J Nucl Med 44: 355-364, 2000.

12. Du XL, Jiang T, Zhao WB, et al: Gene alterations in tumor-associated endothelial cells from endometrial cancer. Int J Mol Med 22: 619-632, 2008

13. Livak KJ and Schmittgen TD: Analysis of relative gene expression data using real-time quantitative PCR and the 2(-Delta Delta C(T)) Method. Methods 25: 402-408, 2001.

14. Kufe D and Weichselbaum R: Radiation therapy: activation for gene transcription and the development of genetic radiotherapy-therapeutic strategies in oncology. Cancer Biol Ther 2 326-329, 2003

15. Raman D, Baugher PJ, Thu YM and Richmond A: Role of chemokines in tumor growth. Cancer Lett 256: 137-165, 2007.

16. Wolff HA, Rolke D, Rave-Fränk M, et al: Analysis of chemokine and chemokine receptor expression in squamous cell carcinoma of the head and neck (SCCHN) cell lines. Radiat Environ Biophys 50: 145-154, 2011.

17. Kryczek I, Wei S, Keller E, Liu R and Zou W: Stroma-derived factor (SDF-1/CXCL12) and human tumor pathogenesis. Am J Physiol Cell Physiol 292: C987-C995, 2007.

18. Chang CC, Lerman OZ, Thanik VD, et al: Dose-dependent effect of radiation on angiogenic and angiostatic CXC chemokine expression in human endothelial cells. Cytokine 48: 295-302, 2009

19. Hu X, Li D, Zhang W, et al: Matrix metalloproteinase-9 expression correlates with prognosis and involved in ovarian cancer cell invasion. Arch Gynecol Obstet 286: 1537-1543, 2012.

20. Peng F, Xu Z, Wang J, et al: Recombinant human endostatin normalizes tumor vasculature and enhances radiation response in xenografted human nasopharyngeal carcinoma models. PLoS One 7: e34646, 2012.

21. Pratheeshkumar P and Kuttan G: Vernolide-A inhibits radiation-induced hypoxia-mediated tumor angiogenesis by regulating HIF-1 $\alpha$, MMP-2, MMP-9, and VEGF. J Environ Pathol Toxicol Oncol 30: 139-151, 2011.

22. Badiga AV, Chetty C, Kesanakurti D, et al: MMP-2 siRNA inhibits radiation-enhanced invasiveness in glioma cells. PLoS One 6: e20614, 2011.
23. Kaliski A, Maggiorella L, Cengel KA, et al: Angiogenesis and tumor growth inhibition by a matrix metalloproteinase inhibitor targeting radiation-induced invasion. Mol Cancer Ther 4: $1717-1728,2005$

24. Nilsson MB, Langley RR, Fidler IJ: Interleukin-6, secreted by human ovarian carcinoma cells, is a potent proangiogenic cytokine. Cancer Res 65: 10794-10800, 2005.

25. Lo CW, Chen MW, Hsiao M, et al: IL-6 trans-signaling in formation and progression of malignant ascites in ovarian cancer. Cancer Res 71: 424-434, 2011.

26. Duan Z, Foster R, Bell DA, et al: Signal transducers and activators of transcription 3 pathway activation in drug-resistant ovarian cancer. Clin Cancer Res 12: 5055-5063, 2006.

27. Oh ET, Park MT, Song MJ, et al: Radiation-induced angiogenic signaling pathway in endothelial cells obtained from normal and cancer tissue of human breast. Oncogene: Mar 18, 2013 (Epub ahead of print).

28. Yu YC, Yang PM, Chuah QY, et al: Radiation-induced senescence in securin- deficient cancer cells promotes cell invasion involving the IL-6/STAT3and PDGF-BB/PDGFR pathways. Sci Rep 3: 1675,2013

29. Rofstad EK, Henriksen K, Galappathi K and Mathiesen B: Antiangiogenic treatment with thrombospondin-1 enhances primary tumor radiation response and prevents growth of dormant pulmonary micrometastases after curative radiation therapy in human melanoma xenografts. Cancer Res 63: 4055-4061, 2003.

30. Maxhimer JB, Soto-Pantoja DR, Ridnour LA, et al: Radioprotection in normal tissue and delayed tumor growth by blockade of CD47 signaling. Sci Transl Med 1: 3ra7, 2009.

31. Liebmann J, DeLuca AM, Coffin D, et al: In vivo radiation protection by nitric oxide modulation. Cancer Res 54: 3365-3368, 1994.

32. Isenberg JS, Martin-Manso G, Maxhimer JB and Roberts DD Regulation of nitric oxide signalling by thrombospondin 1: implications for anti-angiogenic therapies. Nat Rev Cancer 9: 182-194, 2009.

33. Kwon M, Hanna E, Lorang D, et al: Functional characterization of filamin a interacting protein 1-like, a novel candidate for antivascular cancer therapy. Cancer Res 68: 7332-7341, 2008.

34. Lu H and Hallstrom TC: Sensitivity to TOP2 targeting chemotherapeutics is regulated by Oct1 and FILIP1L. PLoS One 7: e42921, 2012.

35. Aksoy S, Szumlanski CL and Weinshilboum RM: Human liver nicotinamide $\mathrm{N}$-methyltransferase cDNA cloning, expression, and biochemical characterization. J Biol Chem 269: 14835-14840, 1994.

36. Sun LQ, Coucke PA, Mirimanoff RO and Buchegger F: Fractionated irradiation combined with carbogen breathing and nicotinamide of two human glioblastomas grafted in nude mice. Radiat Res 155: 26-31, 2001.

37. Hoskin PJ, Saunders MI, Phillips H, et al: Carbogen and nicotinamide in the treatment of bladder cancer with radical radiotherapy. Br J Cancer 76: 260-263, 1997.

38. Kassem HSh, Sangar V, Cowan R, Clarke N and Margison GP. A potential role of heat shock proteins and nicotinamide N-methyl transferase in predicting response to radiation in bladder cancer. Int J Cancer 101: 454-460, 2002. 